\title{
ANALISA PERBAIKAN TATA LETAK GUDANG COIL DENGAN METODE CLASS BASED STORAGE
}

\author{
Rosihin*, Ma'arij, Dadi Cahyadi, Supriyadi \\ Program Studi Teknik Industri, Fakultas Teknik, Universitas Serang Raya \\ Email: rosihin1080@gmail.com; arijmaarij@gmail.com; dadicahyadi2012@gmail.com; \\ supriyadi@unsera.ac.id
}

Artikel masuk : 20-11-2021

Artikel direvisi : 23-12-2021
${ }^{*}$ Penulis Korespondensi

Artikel diterima : 26-12-2021

\begin{abstract}
Abstrak -- Pengaturan tata letak mempunyai peranan penting dalam mempercepat proses operasi suatu sistem. Sistem pengaturan tata letak coil yang menggunakan random storage masih berdampak pada perusahaan seperti tingkat waktu dan kelelahan pekerja. Penempatan produk yang belum sesuai dengan spesifikasi tempat membuat proses kerja yang lama seperti pada saat loading shipment, handling coil dari line packing dan pada proses transfer ke intermediate. Penelitian ini bertujuan untuk mengefektifkan sistem tata letak coil sehingga dapat mengoptimalkan sistem kerja. Penelitian menggunakan metode class based storage yang membagi produk ke dalam tiga klasifikasi yaitu fast moving, medium moving, dan slow moving. Klasifikasi diawali dengan mengurutkan material berdasarkan frekuensi perpindahan. Perubahan pengaturan tata letak coil mampu memberikan tingkat efisiensi yang lebih baik dibandingkan dengan random storage. Perbandingan waktu shipment lebih cepat dari area fast moving ke area shipment yaitu memakan waktu tempuh 1 menit. Tingkat efisiensi jarak mencapai 66\% jika fast moving ditempatkan ke area C4 dan 29\% jika fast moving ditempatkan di C2. Pengaturan dengan pendekatan class based storage mampu memberikan hasil yang optimal terkait dengan efisiensi jarak.
\end{abstract}

Kata kunci: Class Based Storage; Efisiensi Jarak; Fast Moving; Medium Moving; Slow Moving

\begin{abstract}
Layout settings have an important role in accelerating the operational process of a system. The coil layout arrangement system that uses random storage still impacts the company, such as the level of time and worker fatigue. Product placement that is not in accordance with the specifications of the place makes a long work process such as during loading shipments, handling coils from the packing line and in the transfer process to intermediate. This study aims to streamline the coil layout system to optimize the work system. The research uses a class-based storage method that divides products into three categories: fast moving, medium moving, and slow moving. Classification begins with sorting the material based on the frequency of displacement. Changes in coil layout settings can provide a better efficiency level than random storage. The comparison of the shipping time is faster from the fast moving area to the shipment area, which takes 1 minute. The distance efficiency level reaches $66 \%$ if fast moving is placed in the C4 area and 29\% if fast moving is placed in C2. Settings with a class based storage approach are able to provide optimal results related to distance efficiency.
\end{abstract}

Keywords: Class Based Storage; Distance Efficiency; Fast Moving; Medium Moving; Slow Moving

\section{PENDAHULUAN}

Gudang memainkan peran penting dalam dalam manajemen rantai pasokan karena terikat dengan pengiriman produk dari pabrik ke pelanggan sambil memastikan keamanan produk (Dharmapriya \& Kulatunga, 2011). Dalam sistem pergudangan, tata letak produk mempunyai peranan yang penting dalam memperlancar proses pengiriman. Proses pengambilan produk diperkirakan menyumbang biaya distribusi $55 \%$ dari total biaya operasi warehouse (Tompkins et al., 2010) sampai $65 \%$ (Coyle et al., 2003) dari total biaya operasi gudang. Desain gudang dan prinsip manajemen dapat memainkan peran 
penting dalam meningkatkan efisiensi operasi; mengurangi kelelahan karyawan dan meningkatkan tingkat layanan pelanggan (De Koster et al., 2017).

Tujuan perencanaan gudang adalah mengurangi biaya penanganan material dan meningkatkan pemanfaatan ruang (Gu et al., 2007). Pengaturan tata letak gudang dalam mempermudah proses pencarian produk, penyimpanan maupun pengeluaran produk (Johan \& Suhada, 2018). Pengelolaan yang baik juga akan berdampak pada tingkat efektivitas dan efisiensi operasi (Setyawan \& Fauzi, 2020).

Salah satu perusahaan yang bergerak dalam dalam bidang manufaktur (otomotif) juga mempunyai kendala dalam mengelola sistem pergudangan produk jadi. Perusahaan ini mempunyai 3 jenis produk yaitu Cold Rolled Steel, Hot-Dip Galvanized Steel dan Hot-Dip Galvannealed Steel yang digunakan untuk membuat body mobil dalam dunia otomotif. Permintaan produk yang terus berkembang, perusahaan dituntut menghasilkan produk yang berkualitas baik dan sampai ditangan konsumen sesuai dengan jadwal yang telah ditentukan.

Sistem pergudangan mempunyai fungsi menjaga kualitas produk selama proses penyimpanan dan mengirimkan produk sesuai dengan jadwal yang telah ditentukan. Sistem pergudangan yang ada dianggap manajemen masih kurang optimal terutama pada proses shipment pada produk coil. Berdasarkan hasil wawancara menunjukkan permasalahan waktu dan kelelahan pekerja menjadi faktor yang banyak dikeluhkan pada proses shipment sehingga mengganggu jadwal pengiriman produk.

Class Based Storage merupakan kebijakan penyimpanan yang banyak digunakan berdasarkan klasifikasi jenis produk dan menetapkan penyimpanan produk yang acak (Xiao \& Zheng, 2010). Model ini membagi item yang disimpan ke dalam kelas yang berbeda berdasarkan kurva permintaan $A B C$. Dalam kasus penyimpanan berbasis kelas $A B C$, sejumlah kecil produk dengan permintaan tinggi dikelompokkan sebagai produk kelas A dan kemudian disimpan di wilayah gudang yang paling dekat dengan depot (posisi masuk dan keluar). Item permintaan rendah, dikelompokkan sebagai item kelas-C, disimpan di wilayah terjauh dari depot. Dalam setiap kelas, item disimpan secara acak (Yu et al., 2015). Penggunaan metode class based storage mampu mempercepat proses perpindahan jarak 10\% (Septiani et al., 2019) hingga 25\% (Sujana et al., 2014) dibandingkan metode yang diterapkan perusahaan.

Penerapan metode class based storage mampu mengurangi waktu pengambilan lebih besar dibandingkan dengan metode dedicated storage dan random storage (Meghelli-Gaouar \& Sari, 2010; Sooksaksun et al., 2012). Metode ini lebih mudah diimplementasikan daripada metode volume-based storage karena tidak memerlukan daftar lengkap unit penyimpanan stok yang diperingkat berdasarkan volume dan membutuhkan lebih sedikit waktu untuk mengelola daripada menggunakan metode volume-based storage. Unit penyimpanan stok hanya perlu diklasifikasikan ke dalam beberapa kelas penyimpanan berdasarkan tingkat permintaan yang diharapkan (Petersen et al., 2004). Efektivitas class based storage dapat dicapai dengan mengintegrasikan traversal routing karena tingkat kemudahan penggunaannya dan memberikan kinerja yang mendekati optimal.

Penelitian ini bertujuan untuk memberikan perbaikan tata letak di gudang menggunakan class based storage khususnya tata letak coil. Secara keseluruhan tata letak coil ini melibatkan pembagian area ada dalam warehouse agar mempermudah dalam proses shipment, meletakkan dari area packing dan mengurangi beban kerja operator. Penerapan tata letak yang baik, diharapkan akan dapat menekan waktu yang dibutuhkan dalam suatu produksi dan tenaga yang harus dikeluarkan oleh pekerja.

\section{METODE PENELITIAN}

Penelitian ini berkaitan dengan tata letak coil coil pada area departmentt Finishing pada sebuah perusahaan manufaktur di daerah Banten. Sistem pengaturan yang diterapkan sekarang belum optimal sehingga menyebabkan terganggunya proses loading shipment, handling coil dari line CPL (Coil Packing Line) dan transfer coil ke intermediate. Pengaturan kembali berdasarkan metode class based storage.

Operasi gudang biasanya diatur oleh salah satu dari tiga kebijakan penyimpanan: randomized storage, dedicated storage, dan class-based storage. Class-based storage adalah perpaduan antara penyimpanan randomized storage dan dedicated storage. Inventaris diberi kelas berdasarkan beberapa kriteria (yaitu, permintaan, jenis produk, ukuran) dan setiap kelas diberi blok lokasi penyimpanan. Dalam setiap blok lokasi penyimpanan, bahan disimpan secara acak (Larson et al., 1997).

Tujuan model ini adalah adalah untuk mengelompokkan material dengan karakteristik yang sama dan mengalokasikan ruang lantai berdasarkan prioritas kelompok. Prosedur klasifikasi berusaha untuk meningkatkan pemanfaatan ruang lantai dengan membatasi efek 'honeycombing' (Tompkins \& Smith, 1998), dan mengurangi penanganan material dengan memberi 
peringkat item berdasarkan kebutuhan ruang penyimpanan dan throughput. Setiap kelas ditugaskan ke wilayah penyimpanan; namun, di dalam wilayah penyimpanan, materi disimpan secara acak. Penyimpanan acak dalam wilayah memberikan fleksibilitas untuk mengakomodasi variasi tingkat inventaris untuk bahan yang ditugaskan ke kelas. Dengan demikian, kebijakan penyimpanan berbasis kelas yang diusulkan meningkatkan pemanfaatan ruang lantai, menurunkan biaya penanganan material, dan meningkatkan fleksibilitas (Tompkins et al., 2010).

Penentuan model perencanaan menggunakan konsep klasifikasi ABC. Semua item produk mempunyai variasi masing-masing sehingga tidak memerlukan tingkat pengendalian yang sama. Konsep ABC mengadopsi dari implementasi hukum pareto. Hukum Pareto menyiratkan bahwa sekitar 10 hingga 20 persen dari item inventaris perusahaan menyumbang sekitar 60 hingga 80 persen dari biaya inventarisnya. Kelas A merupakan produk bervolume tinggi yang relatif sedikit tetapi memberikan kontribusi omzet sekitar 60\%$80 \%$. Produk dengan volume sedang, kira-kira 30 persen dari produk itu, menyumbang sekitar 25 sampai 35 persen dari biaya persediaan perusahaan diklasifikasikan sebagai item B. Produk bervolume rendah, sekitar 50 sampai 60 persen dari produk-produk tersebut, hanya mewakili 5 sampai 15 persen dari omzet persediaan perusahaan dan diklasifikasikan sebagai produk C (Reid \& Sanders, 2015).

\section{HASIL DAN PEMBAHASAN}

Produk utama perusahaan adalah Cold Rolled Coil (CRC) dan Hot Rolled Pickled and oiled (HRPO) yang telah dilapisi dengan seng ( $\mathrm{Zn})$ dan Cold Rolled Coil (CRC) yang telah diproses annealing untuk memenuhi pasar industri otomotif. Berdasarkan wawancara dengan pihak perusahaan, penyebab pengaturan tata letak yang kurang baik disebabkan kurangnya material handling sedangkan produk yang diletakkan dan yang diambil sangat banyak sehingga membutuhkan waktu lama dan akses lifter crane terbatas; kebutuhan operator tambahan atau subcont untuk membantu proses loading dan handling hoil dari line CPL (Coil Packing Line) karena pekerjaan saat ini yang dikerjakan oleh dua orang dan terkadang leader pun membantu pekerjaan operator; metode FIFO tidak berjalan dengan baik dan efisien yang diakibatkan keterbatasan warehouse dan pemanfaatan tempat yang tidak maksimal sehingga tidak ada ruang untuk menyimpan produk yang ditahan (Hold); dan produk diletakkan secara acak sehingga menyebabkan sulitnya pada saat pengambilan produk, tidak ada pemisah antara tipe dan jenis produk yang berdampak kondisi warehouse tidak tertata dan berantakan.

Analisis ABC membantu mengelompokkan produk sesuai dengan tingkat kepentingan penyimpanan produk coil. Coil dikelompokkan dan disimpan sesuai klasifikasinya. Hal ini akan memudahkan jangkauan bagi pekerja, memaksimalkan tempat penyimpanan, dan mengurangi waktu penyiapan. Data yang digunakan merupakan data transaksi produk selama 2 bulan (Februari 2021Maret 2021) (Tabel 1 dan Tabel 2).

Tabel 1. Total Frekuensi Coil Keluar

\begin{tabular}{cclr}
\hline No. & Jenis Coil & Tipe coil & Total \\
\hline 1 & CR & Inner & 1.639 \\
& & Outer & 215 \\
& & Secondary & 61 \\
2 & GA & Inner & 614 \\
& & Outer & 170 \\
& & Secondary & 38 \\
3 & \multirow{2}{*}{ GI } & Inner & 513 \\
& & Outer & 0 \\
& & Secondary & 26 \\
\hline & Jumlah & & 3.276 \\
\hline
\end{tabular}

Tabel 2. Tipe Saddle per Tipe jenis Coil

\begin{tabular}{|c|c|c|c|}
\hline $\begin{array}{c}\text { Jenis } \\
\text { Coil }\end{array}$ & Tipe coil & Tipe Saddle & \\
\hline \multirow[t]{3}{*}{$\mathrm{CR}$} & Inner & $700 \mathrm{~mm} 900 \mathrm{~mm} 1000 \mathrm{~mm}$ & $1400 \mathrm{~mm}$ \\
\hline & Outer & $900 \mathrm{~mm} 1000 \mathrm{~mm}$ & $1400 \mathrm{~mm}$ \\
\hline & Secondary & $700 \mathrm{~mm} 900 \mathrm{~mm} 1000 \mathrm{~mm}$ & $1400 \mathrm{~mm}$ \\
\hline \multirow[t]{3}{*}{ GA } & Inner & $700 \mathrm{~mm} 900 \mathrm{~mm} 1000 \mathrm{~mm}$ & $1400 \mathrm{~mm}$ \\
\hline & Outer & $900 \mathrm{~mm} 1000 \mathrm{~mm}$ & $1400 \mathrm{~mm}$ \\
\hline & Secondary & $700 \mathrm{~mm} 900 \mathrm{~mm} 1000 \mathrm{~mm}$ & $1400 \mathrm{~mm}$ \\
\hline \multirow[t]{3}{*}{ Gl } & Inner & $900 \mathrm{~mm} 1000 \mathrm{~mm}$ & \\
\hline & Outer & $1000 \mathrm{~mm}$ & \\
\hline & Secondary & $900 \mathrm{~mm} 1000 \mathrm{~mm}$ & \\
\hline
\end{tabular}

Seluruh tipe coil yang sama disatukan dan dijumlahkan untuk mencegah pengulangan. Sisa coil yang tidak keluar 180 untuk pengiriman beberapa bulan kedepan, inspeksi ulang, relabel dan unpacking. Klasifikasi produk berdasarkan konsep $\mathrm{ABC}$ diperoleh dengan cara klasifikasi $\mathrm{A}$ (coil yang dikategorikan dalam kelompok $A$ adalah coil yang total kumulasi transaksinya mencapai $61 \%$ dari total seluruh transaksi selama 2 periode sehingga rumus klasifikasi $A=61 \%$ transaksi keluar seluruh coil); klasifikasi B (coil yang dikategorikan dalam kelompok $B$ adalah coil yang total akumulasi transaksi mencapai 30\% dari total seluruh transaksi selama 2 periode sehingga rumus klasifikasi $B=30 \%{ }^{*}$ transaksi seluruh total coil) dan klasifikasi C (coil yang dikategorikan dalam kelompok $\mathrm{C}$ adalah coil yang total akumulasi transaksi hanya sebesar 9\% dari total seluruh transaksi selama 2 periode sehingga 
rumus klasifikasi $\mathrm{C}=9 \%$ *transaksi seluruh total coil) (Tabel 3, dan Tabel 4). Berdasarkan total coil yang masuk sejumlah 3.276, jumlah tersebut sama dengan jumlah masing-masing tipe coil yang masuk ke area Finishing.

Tabel 3. Klasifikasi Coil dengan Urutan Jumlah

\begin{tabular}{cccc}
\hline No & Tipe Coil & Total & Class \\
\hline 1 & Inner (CR) & 1.639 & $\mathrm{~A}$ \\
2 & Outer (CR) & 215 & $\mathrm{~A}$ \\
3 & Inner (GA) & 614 & $\mathrm{~B}$ \\
4 & Outer (GA) & 170 & $\mathrm{~B}$ \\
5 & Inner (GI) & 513 & $\mathrm{~B}$ \\
6 & Secondary (CR) & 61 & $\mathrm{C}$ \\
7 & Secondary (GA) & 38 & $\mathrm{C}$ \\
8 & Secondary (GI) & 26 & $\mathrm{C}$ \\
\hline
\end{tabular}

Tabel 4. Klasifikasi ABC Berdasarkan Jumlah

\begin{tabular}{ccc}
\hline Class & Coil & Total \\
\hline A & CR & 1.854 \\
B & GA & 784 \\
B & Gl & 513 \\
C & Secondary & 125 \\
\hline Total & & 3.276 \\
\hline
\end{tabular}

Perancangan tata letak pada warehouse mengikuti metode class based storage dimana produk ditempatkan menurut klasifikasi produk, dimana produk class A ditempatkan dekat dengan pintu keluar agar mempercepat proses outbound, dan sebaliknya class $\mathrm{C}$ ditempatkan jauh dari area outbound. Area C1, C2, C3, C4, dan C5 merupakan usulan tata letak coil yang tersimpan pada warehouse agar sesuai dengan klasifikasi keluar coil ke customer (Gambar 1). Kekurangannya dari tata letak sebelumnya mulai dari coil secondary yang tersimpan di area dekat dengan Proses loading, adapun dengan spesifikasi coil lebar $1200 \mathrm{~mm}$ disimpan pada saddle $900 \mathrm{~mm}$, lebar $1400 \mathrm{~mm}$ - $1600 \mathrm{~mm}$ masih disimpan pada saddle $1000 \mathrm{~mm}$, dan lebar coil $900 \mathrm{~mm}$ disimpan pada saddle $700 \mathrm{~mm}$ sehingga sering terjadinya downtime pengambilan produk di area packing dikarenakan harus moving coil yang tidak sesuai dengan spesifikasi saddle, coil secondary yang ditempatkan pada area dekat shipment, penempatan produk pada saat ini menghambat proses shipment dan penempatan coil dari area packing.

Penggunaan tata letak ini cukup mengatasi masalah yang sebelumnya timbul dan memberikan beberapa kemudahan terhadap flow process pada gudang. Untuk mengatasi masalah yang ada maka dibuatlah usulan tata letak agar coil dengan klasifikasi yang tinggi dekat dengan area outbound sehingga mempercepat pekerjaan. Coil yang dengan spesifikasi berat diatas 4 Ton disimpan pada Tier 1 untuk Tier 2 berat nya harus lebih kecil dari Tier 1 agar tidak merusak produk pada Tier 1. Adapun penempatan dengan class $A$ pada area C4-C5, class B ditempatkan pada area C2-C3 dan class $\mathrm{C}$ ditempatkan pada area $\mathrm{C} 1$.

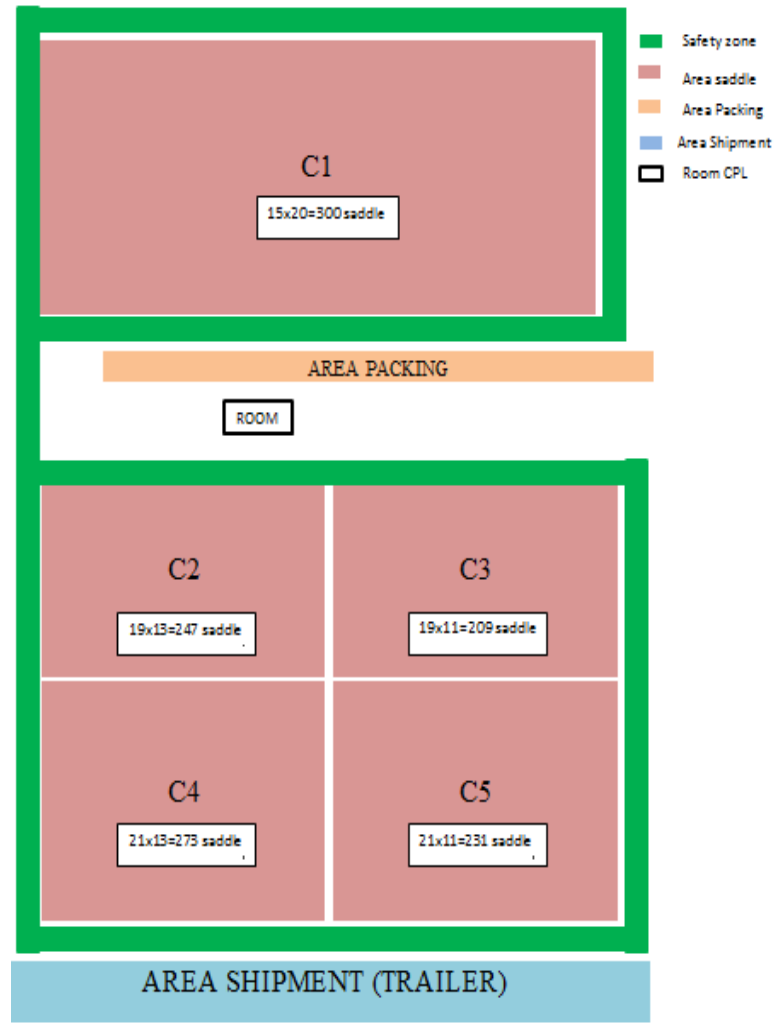

Gambar 1. Layout Warehouse

Klasifikasi A ( fast moving) disimpan pada area yang jauh dari area shipment maka jika jarak dari C1 ke area shipment adalah $144 \mathrm{~m}$, waktu yang dibutuhkan untuk bisa sampai dari $\mathrm{C} 1$ ke area shipment dengan menggunakan crane adalah selama 144 detik maka kecepatan crane adalah $\mathrm{V}=144 \mathrm{~m} / 144$ detik $=0,10 \mathrm{~m} /$ detik. Crane mengambil coil dari area $\mathrm{C} 1$ menuju area shipment, jarak dari $\mathrm{C} 1 \mathrm{ke}$ area shipment adalah $144 \mathrm{~m}$, kecepatan crane adalah $0,10 \mathrm{~m} / \mathrm{s}$ maka waktu tempuh untuk sampai ke area shipment $(\mathrm{T})$ adalah $144 \mathrm{~m} / 0,10 \mathrm{~m} /$ detik $=144$ detik

Apabila klasifikasi A (fast moving) disimpan dekat dengan area shipment dan jarak dari C4 ke area shipment adalah $48 \mathrm{~m}$, waktu yang dibutuhkan untuk bisa sampai dari C4 ke area shipment dengan menggunakan crane adalah selama 40 detik maka kecepatan crane (V) adalah $48 \mathrm{~m} / 48$ detik $=0,10 \mathrm{~m} /$ detik. Crane mengambil coil dari area C4 menuju area shipment, jarak dari C4 ke area shipment adalah $48 \mathrm{~m}$, kecepatan crane adalah $0,10 \mathrm{~m} / \mathrm{s}$ maka waktu tempuh untuk sampai ke area shipment $(\mathrm{T})$ adalah $48 \mathrm{~m} / 0,10$ $\mathrm{m} /$ detik $=48$ detik. 
Jika klasifikasi B (medium moving) disimpan dekat dengan area shipment dan jarak dari C2 ke area shipment adalah 102,4 m, waktu yang dibutuhkan untuk bisa sampai dari $\mathrm{C} 2 \mathrm{ke}$ area shipment dengan menggunakan crane adalah selama 102 detik maka kecepatan crane adalah $0,10 \mathrm{~m} /$ detik. Crane mengambil coil dari area $\mathrm{C} 2$ menuju area shpment, jarak dari C2 ke area shipment adalah 102,4 m, kecepatan crane adalah $0,10 \mathrm{~m} / \mathrm{s}$ maka waktu tempuh untuk sampai ke area shipment adalah 102 detik.

Setelah diperoleh perhitungan efisiensi waktu dari area pengambilan ke area shipment, apabila coil dengan klasifikasi A (fast moving) disimpan pada area $\mathrm{C} 1$ (yang jauh dari area shipment) maka hasil yang didapatkan dari kecepatannya $0,10 \mathrm{~m} / \mathrm{s}$, untuk dari waktu tempuhnya 144 detik. Apabila coil disimpan pada area C4 (dekat dengan area shipment) kecepatan yang didapatkan $0,10 \mathrm{~m} / \mathrm{s}$ dengan waktu tempuh 48 detik.

efisiensi (\%) $=\frac{\text { layout awal-layout usulan }}{\text { layout awal }} \times 100 \%$

Jarak C1 ke area shipment: $144 \mathrm{~m}$, usulan C4 ke area shipment: $48 \mathrm{~m}$ maka efisiensi (\%) adalah $66 \%$. Jarak $C 1$ ke area shipment: $144 \mathrm{~m}$, usulan C2 ke area shipment: $102 \mathrm{~m}$ maka efisiensi $(\%)=29 \%$. Hasil ini menunjukkan penggunaan class based storage lebih efisien dibandingkan dengan metode random storage (Meghelli-Gaouar \& Sari, 2010; Sooksaksun et al., 2012) yang diterapkan perusahaan. Perbandingan waktu shipment yang cepat dari area fast moving ke area shipment memakan waktu tempuh 1 menit. Penggunaan metode ini juga mampu memperbaiki efisiensi jarak yaitu fast moving dan medium moving ditempatkan pada $\mathrm{C} 1 \mathrm{ke}$ area shipment dengan jarak $144 \mathrm{~m}$ (sebelum perbaikan) menjadi fast moving ditempatkan ke area C4 dengan jarak $48 \mathrm{~m}$ setelah dihitung mendapatkan efisiensi jarak sebesar $66 \%$ sedangkan jika fast moving ditempatkan di C2 mendapatkan efisiensi jarak $29 \%$ (sesudah perbaikan). Kondisi ini berdampak pada efisiensi kerja sehingga mampu mempercepat proses operasi.

Class based storage merupakan kebijakan yang mengklasifikasikan unit penyimpanan stok ke dalam kelas produk, berdasarkan kriteria yang sesuai seperti volume atau tingkat penggunaan. Class based storage mempunyai kemampuan seperti implementasi yang sederhana, pemeliharaan yang dapat dikelola, dan kemampuan untuk mengatasi bauran produk dan variasi permintaan (Le-Duc \& De Koster, 2005). Pengambilan produk berbasis class based storage memiliki waktu tempuh yang lebih rendah untuk mengambil dan mengambil muatan jika dibandingkan dengan metode random storage (Pohl et al., 2011) dan mampu mengoptimalkan sejumlah sejumlah item diskrit untuk setiap kelas untuk berbagai jenis permintaan $\mathrm{ABC}$ dan bentuk gudang (Hsieh \& Tsai, 2006). Solusi berbasis class based memberikan kinerja lebih baik dibandingkan pendekatan dedicated pada saat sistem mengalami fluktuasi unit penyimpanan stok yang tinggi (Muppani \& Adil, 2008).

Kekuatan kebijakan class based storage adalah dalam mengambil keuntungan dari logika dedicated storage, sambil menghindari tugastugas yang melelahkan (Petersen et al., 2005). Untuk ini, kebijakan berbasis class based storage mengklasifikasikan produk berdasarkan beberapa kriteria untuk menentukan penempatan produk. Pengklasifikasikan produk untuk penugasan penyimpanan berdasarkan tingkat perputaran produk (Chiang et al., 2011), dan kriteria lain yang digunakan dalam dedicated storage dapat untuk tujuan ini (Bahrami et al., 2019).

\section{KESIMPULAN}

Penyusunan tata letak coil menurut metode class based storage membagi produk menjadi tiga kelas A, B, dan C. Metode ini menjadikan pengaturan tempat menjadi lebih fleksibel yaitu dengan cara membagi tempat penyimpanan. Hasil perhitungan $A B C$ membantu mengatur urutan peletakan Coil. Coil yang mempunyai klasifikasi A akan diletakan dekat dengan jangkauan pekerja saat loading untuk membantu mengurangi jarak jangkauan pekerja, sehingga waktu loading lebih cepat dan meminimalisir kelelahan pada saat proses pengambilan Coil. Klasifikasi B disimpan pada area C2 dan C3 (pertengahan area), dan klasifikasi $\mathrm{C}$ disimpan pada area $\mathrm{C} 1$ atau tempat yang jauh dari area shipment. Pengaturan ulang ini memberikan efisiensi jarak sebesar $66 \%$ jika fast moving ditempatkan ke area C4 dan $29 \%$ jika fast moving ditempatkan di C2. Penelitian ini dapat dilanjutkan dengan memperhatikan kriteria lain seperti keterbatasan sumber daya atau kombinasi penyimpanan, batching, dan perutean.

\section{DAFTAR PUSTAKA}

Bahrami, B., Piri, H., \& Aghezzaf, E.-H. (2019). Class-based storage location assignment: an overview of the literature. 16th International Conference on Informatics in Control, Automation and Robotics (ICINCO 2019), 390-397. https://biblio.ugent.be/publication/8642650

Chiang, D. M.-H., Lin, C.-P., \& Chen, M.-C. (2011). The adaptive approach for storage assignment by mining data of warehouse management system for distribution centres. 
Enterprise Information Systems, 5(2), 219234.

https://doi.org/10.1080/17517575.2010.537 784

Coyle, J. J., Bardi, E. J., \& Langley, C. J. (2003). The Management of Business Logistics: A Supply Chain Perspective. SouthWestern/Thomson Learning. https://books.google.co.id/books?id=uoV3A QAACAAJ

De Koster, R. B. M., Johnson, A. L., \& Roy, D. (2017). Warehouse design and management. International Journal of Production Research, 55(21), 6327-6330. https://doi.org/10.1080/00207543.2017.137 1856

Dharmapriya, U. S. S., \& Kulatunga, A. K. (2011). New strategy for warehouse optimizationlean warehousing. Proceedings of the 2011 International Conference on Industrial Engineering and Operations Management, 513-519.

http://www.iieom.org/ieom2011/pdfs/IEOM0 76.pdf

Gu, J., Goetschalckx, M., \& McGinnis, L. F. (2007). Research on warehouse operation: A comprehensive review. European Journal of Operational Research, 177(1), 1-21. https://doi.org/10.1016/j.ejor.2006.02.025

Hsieh, L., \& Tsai, L. (2006). The optimum design of a warehouse system on order picking efficiency. The International Journal of Advanced Manufacturing Technology, 28(5), 626-637. https://doi.org/10.1007/s00170004-2404-0

Johan, J., \& Suhada, K. (2018). Usulan perancangan tata letak gudang dengan menggunakan metode class-based storage (studi kasus di pt heksatex indah, cimahi selatan). Journal of Integrated System, 1(1), 52-71.

https://journal.maranatha.edu/index.php/jis/ article/view/989

Larson, T. N., March, H., \& Kusiak, A. (1997). A heuristic approach to warehouse layout with class-based storage. IIE Transactions, 29(4), 337-348. https://doi.org/10.1080/0740817970896633 9

Le-Duc, T., \& De Koster, R. (M. )B. M. (2005). Travel distance estimation and storage zone optimization in a 2-block class-based storage strategy warehouse. International Journal of Production Research, 43(17), 3561-3581.

https://doi.org/10.1080/0020754050014289 4

Meghelli-Gaouar, N., \& Sari, Z. (2010).
Assessment of performance of a classbased storage in a flow-rack AS/RS. Journal of Studies on Manufacturing, 1(2), 100-107. https://www.researchgate.net/publication/26 0300977

Muppani, V. R., \& Adil, G. K. (2008). Efficient formation of storage classes for warehouse storage location assignment: A simulated annealing approach. Omega, 36(4), 609618.

https://doi.org/10.1016/j.omega.2007.01.00 6

Petersen, C. G., Aase, G. R., \& Heiser, D. R. (2004). Improving order-picking performance through the implementation of class-based storage. International Journal of Physical Distribution \& Logistics Management, 34(7), 534-544. https://doi.org/10.1108/0960003041055223 0

Petersen, C. G., Siu, C., \& Heiser, D. R. (2005). Improving order picking performance utilizing slotting and golden zone storage. International Journal of Operations \& Production Management, 25(10), 997-1012. https://doi.org/10.1108/0144357051061949 1

Pohl, L. M., Meller, R. D., \& Gue, K. R. (2011). Turnover-based storage in non-traditional unit-load warehouse designs. IIE Transactions, 43(10), 703-720. https://doi.org/10.1080/0740817X.2010.549 098

Reid, R. D., \& Sanders, N. R. (2015). Operations Management: An Integrated Approach. Wiley.

https://books.google.co.id/books?id=9OpRC gAAQBAJ

Septiani, W., Dahana, A. E., \& Adisuwiryo, S. (2019). Perancangan Model Tata Letak Gudang Bahan Baku Dengan Metode Class Based Storage dan Simulasi Promodel. Jurnal IImiah Teknik Industri, 6(2), 106-116. https://doi.org/10.24912/jitiuntar.v6i2.4118

Setyawan, W., \& Fauzi, F. R. (2020). Efektivitas Tata Letak Gudang Baru untuk Menekan Tingkat Kerusakan Produk Menggunakan Metode Class Based Storage. Jurnal Media Teknik Dan Sistem Industri, 4(2), 100-106. https://doi.org/10.35194/jmtsi.v4i2.1074

Sooksaksun, N., Kachitvichyanukul, V., \& Gong, D.-C. (2012). A class-based storage warehouse design using a particle swarm optimisation algorithm. International Journal of Operational Research, 13(2), 219-237. https://doi.org/10.1504/IJOR.2012.045188

Sujana, A. P., Damayanti, D. D., \& Astuti, M. D. (2014). Usulan Perbaikan Alokasi 
Penyimpanan Barang Dengan Metode Class Based Storage Pada Gudang Bahan Baku 1 PT SMA. Jurnal Rekayasa Sistem \& Industri $(J R S I)$, $1(02)$, $1-7$. https://jrsi.sie.telkomuniversity.ac.id/JRSI/art icle/view/11

Tompkins, J. A., \& Smith, J. D. (1998). The Warehouse Management Handbook. Tompkins Press. https://books.google.co.id/books?id=oHkA1 5BCY9MC

Tompkins, J. A., White, J. A., Bozer, Y. A., \& Tanchoco, J. M. A. (2010). Facilities Planning. Wiley.
xBlq6Qm2SQC

Xiao, J., \& Zheng, L. (2010). A correlated storage location assignment problem in a singleblock-multi-aisles warehouse considering BOM information. International Journal of Production Research, 48(5), 1321-1338. https://doi.org/10.1080/0020754080255573 6

Yu, Y., de Koster, R. B. M., \& Guo, X. (2015). Class-Based Storage with a Finite Number of Items: Using More Classes is not Always Better. Production and Operations Management, 24(8), 1235-1247. https://doi.org/10.1111/poms.12334 